\title{
O papel do coordenador pedagógico numa experiência de formação colaborativa de professores ${ }^{1}$
}

\author{
The pedagogical coordinator's role in an experience of collaborative teacher \\ training
}

Patricia Aparecida Bioto-Cavalcanti Doutora em Educação pelo EHPS-PUC/SP Professora do PROGEPE-UNINOVE Residente em Guarulhos-SP, Brasil. patriciacavalcanti@uni9.pro.br

Michele Pimentel Olim Mestre em Educação pelo PROGEPE-UNINOVE Coordenadora pedagógica na Prefeitura de São Paulo Residente em São Paulo-SP, Brasil. micapimentel1705@gmail.com

Resumo: Neste artigo o foco de estudo é a atuação do coordenador pedagógico como elemento articulador numa experiência de formação colaborativa de professores num Centro de Educação Infantil (CEI) da rede municipal de ensino de São Paulo em 2018. Segundo as orientações para o planejamento Projetos especiais de Ação (PEAs), em se considerando a realidade do CEI, o tema foi o desenvolvimento infantil segundo Maria Montessori. Estabelecido o foco da pesquisa-formação, a pauta dos encontros manteve-se para os professores dos períodos da manhã e tarde, tendo sido comportadas alterações ocasionais durante o processo. Participaram do pesquisa-formação 45 professores da CEI mais a coordenadora pedagógica. Todos os dados foram posteriormente organizados e analisados em categorias de análise que emergiram das discussões dos encontros. Pode-se concluir da experiência que foi possível construir, (re) significar e (re) avaliar o trabalho pedagógico, mediado pela ação do coordenador.

Palavras-chave: Coordenador Pedagógico. Educação Infantil. Maria Montessori. Pesquisa-Formação.

Abstract: In this article the focus of study is the work of the pedagogical coordinator as an articulating element in a collaborative educational experience of teachers in Early Childhood Education Center (CIS) of the city of São Paulo teaching in 2018. Under the guidelines for planning special works Action (PEAs), considering the reality of the CIS, the theme was child development according to Maria Montessori. Established the focus of research-training, the agenda of the meetings remained for teachers of the morning and afternoon, having been behaved occasional changes during the process. Thirty-five CIS teachers plus the pedagogical coordinator took part in the research-training. All the data were later organized and analyzed in categories of analysis that emerged from the discussions of the meetings. One can conclude from the experience that it was possible to construct, (re) signify and (re) evaluate the pedagogical work, mediated by the coordinator's action.

Key-words: Pedagogical Coordinator. Child education. Maria Montessori. Research-Training.

\footnotetext{
1 Este artigo é um recorte da dissertação de mestrado de Michele Pimentel Olim, A formação continuada de professores em um Centro de Educação Infantil (CEI) do município de São Paulo, defendida em 2019 no PROGEPE/UNINOVE.
} 


\section{Introdução}

Dentre as múltiplas funções que o coordenador pedagógico exerce numa escola pode-se apontar a de gestor, mediador e formador de professores. Neste artigo elege-se como foco de estudo a atuação do coordenador pedagógico como elemento articulador numa experiência de formação colaborativa de professores num Centro de Educação Infantil (CEI) da rede municipal de ensino de São Paulo que ocorreu em 2018.

Tal formação inseriu-se numa prática de formação continuada de professores da rede pública paulistana, os Projetos especiais de Ação (PEAs). Os PEAs são elaborados anualmente, sempre no início do ano letivo. Deve contemplar questões, desafios, interesses, do grupo de professores, considerando a realidade da escola, os objetivos do Projeto Pedagógico da escola, em articulação com as diretrizes da Secretaria Municipal da Educação e outras estaduais e federais. Professores e equipe gestora participam da proposição e da elaboração do PEA e é função precípua do coordenador pedagógico levá-lo a diante.

Segundo as orientações para o planejamento do PEA, em se considerando a realidade do CEI em questão, o tema da pesquisa-formação aqui retratada foi o desenvolvimento infantil segundo as contribuições de Maria Montessori.

Estabelecido o foco da pesquisa-formação, acertou-se no calendário do PEA da unidade a disposição dos momentos formativos, dentre as demais demandas escolares. A pauta das formações manteve-se para os professores dos dois períodos: manhã e tarde, tendo sido comportadas alterações ocasionais durante o processo. Participaram do pesquisa-formação 45 professores da CEI mais a coordenadora pedagógica. Tudo que foi produzido durante os encontros foi gravado e registrado em notas de observação e acompanhamento pela própria coordenadora. Foram produzidos também registros escritos individuais de avaliação de cada encontro em que cada professor elaborava e externava sua opinião sobre os elementos relevantes da pauta trabalhada. Todos os dados foram posteriormente organizados e analisados em categorias de análise que emergiram das discussões dos encontros a luz das contribuições de Maria Montessori.

Neste texto, num primeiro momento, tecer-se-á considerações sobre o papel do coordenador pedagógico no desenvolvimento de uma formação colaborativa de professores. Num segundo momento será contemplado o universo, os sujeitos e o desenvolvimento da pesquisa-formação em tela. Em seguida, serão apresentadas as categorias de análise que dão a ver 
os impactos e resultados da pesquisa-formação nos professores. Finda-se o texto considerando-se as contribuições da experiência realizada e o papel do coordenador pedagógico na mesma.

\section{O coordenador pedagógico e a formação centrada na escola}

$\mathrm{Na}$ atualidade dois modelos de formação continuada de professores se fazem presentes nas secretarias de educação estaduais e municipais no Brasil (DAVIS, 2012): a formação centrada no sujeito do professor e a formação centrada nas equipes pedagógicas das escolas. Em sua grande maioria o que se percebe é que as práticas de formação continuada levadas a efeito pelas secretarias de educação tem primado pela centralidade no sujeito do professor, ou seja, é uma formação muito mais individualizada do que comunitária (DAVIS, 2012).

Ao se afirmar que a formação continuada tem o papel de auxiliar grandemente no desenvolvimento de características éticas, político e pedagógicas essenciais para o exercício profissional está-se indo ao encontro da ideias que defendem a figura do professor como um sujeito social e político com função social relevante, tanto em termos ideológicos quanto materiais. Aposta-se, desta forma, no peso da função docente para a existência social partindo-se do princípio que o estatuto humano depende da produção cultural e das apropriações de cada homem da herança cultural disponível. Preparar o professor para servir como intermediário neste processo de humanização, de apropriação sócio-cultural é tarefa ininterrupta, que de maneira alguma pode-se esgotar numa experiência de formação inicial.

O desenvolvimento subjetivo do professor é fundamental para o exercício da docência. Colocar em pauta duvidas, dificuldades, perspectivas, desafios, esperanças, medos e possibilidades apresenta-se como possibilidade de construção de uma subjetividade apoiada no coletivo, onde o trabalho do professor se fundamenta e se executa. Dar voz ao professor é o primeiro passo para qualificá-lo como um intelectual da educação. Mais ainda, para qualificá-lo como sujeito que pensa sua própria prática docente, o sentido desta, seu alcance social, seus limites, possibilidades, certezas e apostas.

As práticas de formação centradas nas equipes escolares recaem no coletivo de professores de cada escola. Papel central é atribuído nestes modelos à figura do coordenador pedagógico. De acordo com as demandas que se apresentam, ele mobiliza a equipe para elaborar e reelaborar o projeto pedagógico da escola. Auxilia também na proposição e implementação de medidas que segundo o grupo são necessárias. 
Para Libâneo (2003), acompanhar a formação continuada é uma tarefa que envolve diretamente o coordenador pedagógico da escola, pois é na escola que os professores enfrentam e resolvem problemas, elaboram e modificam procedimentos, criam e recriam estratégias e planos de trabalho, e com isso repensam sua prática pedagógica.

Conforme Kramer (2005), a ideia de formação específica para professores de educação infantil foi necessária para assegurar o direito de todas as crianças à educação com qualidade, trazendo recomendações às políticas de Educação Infantil e de formação de profissionais.

No Brasil, a formação para quem trabalha com Educação Infantil, principalmente nos centros de educação infantil (CEI), nas décadas de 1970 e 1980, era inexistente como habilitação profissional no curso de Pedagogia e insuficiente para o desenvolvimento do trabalho com crianças. Atualmente, a formação para atuar na educação infantil é contemplada nos cursos de Pedagogia, em que se formam os professores deste nível e da primeira etapa do ensino fundamental, bem como o gestor e o pesquisador em educação. Em meio a tantas demandas, a formação para educação infantil ainda permanece insuficiente.

Perante tal cenário optou-se, no Brasil, e mesmo em muitos países, por enfatizar a formação continuada dos professores da educação infantil, e também de outros níveis de ensino. Cursos são oferecidos pelas redes públicas de educação, palestras ministradas, jornadas formativas, espaço para formação em ambiente de trabalho, etc. Muitas mudanças vêm ocorrendo nos últimos anos quando se fala em formação continuada de professores de educação infantil. O professor precisa ter competência (superando o improviso, o amadorismo e a mediocridade), ser preciso, ter disciplina metodológica e criatividade para entender e trabalhar o conhecimento conforme o contexto em que aparece, de acordo com Arce (2009, p. 54).

As pesquisas no Brasil mostram que a atuação da professora junto às crianças pequenas no cotidiano das creches e pré-escolas também depende de outros fatores, como por exemplo: a divisão de trabalho entre os adultos na instituição; o número de crianças por professora e o número de crianças e adultos em cada sala; o currículo adotado; a organização do tempo; as rotinas seguidas no cotidiano; a organização e o arranjo dos espaços; os recursos educativos disponíveis (equipamentos, materiais, brinquedos); a presença e atuação do coordenador pedagógico; a gestão da instituição; a relação com as famílias e a comunidade; a gestão da rede municipal e/ou da entidade conveniada. (CAMPOS, 2018, p. 14).

Segundo Bissaco (2012) a formação continuada deve levar o professor a ser um professor reflexivo, que reconhece seu potencial e oportuniza situações de aprendizagem que o levem a reconhecer-se como professor reflexivo, construindo conhecimento a partir da reflexão de sua prática. 
Seguindo tal princípio, a coordenadora pedagógica de um CEI de São Paulo, em consonância com as diretrizes da rede, das características e necessidades da escola, elaborou um plano de formação continuada dos professores. Anualmente o Projeto Especial de Ação é avaliado por todos os envolvidos e pensado para o próximo ano letivo, de modo que busque suprir toda necessidade de formação da unidade escolar, apesar de ainda ser pouco diante de toda especificidade da educação infantil.

$\mathrm{Na}$ função de Coordenadora Pedagógica designada no (CEI) uma das maiores preocupações é a formação de professores durante os Projetos Especiais de Ação (PEA's). Há uma constante preparação e assimilação de conteúdos tanto pela coordenação pedagógica quanto pelos professores para melhorar suas práticas diárias. A coordenação pedagógica da prefeitura de São Paulo recebe formação mensal com uma coordenadora geral, diretamente nas Diretorias Regionais de Educação onde a escola está vinculada.

Se a formação inicial é mal avaliada, é porque não desenvolveu as habilidades, competências e conhecimentos necessários à ação docente. O papel do coordenador pedagógico também é de formar os professores em sala de aula, e as Davis et all colocam que na França e Canadá as funções do coordenador são bem parecidas com as funções dele no Brasil, lembrando que na França existe o consultor escolar, cuja meta é orientar os professores e equipes pedagógicas.

Aparecem algumas das atribuições do coordenador pedagógico, como:

(1) propor programas de estudo; (2) orientar a escolha de métodos, técnicas, equipamentos e materiais didáticos e pedagógicos para favorecer o ensino oferecido; (3) acompanhar as mudanças no campo educacional; (4) verificar a pertinência dos objetivos pedagógicos; (5) verificar os resultados escolares obtidos pelos alunos; (6) projetar, organizar e ministrar cursos de formação de professores; (7) colaborar para o desenvolvimento dos programas de formação continuada oferecidos pelas universidades; e (8) organizar e realizar encontros com professores, verificando suas necessidades e propondo soluções adequadas. (DAVIS et all, 2012, p.16).

\section{A pesquisa-formação: pressupostos, universo, sujeitos, desenvolvimento}

\section{Pressupostos}

$\mathrm{Na}$ pesquisa-formação, o formador não somente observa a pesquisa como intervém como sujeito de ocorrências. Este processo faz com que a pesquisa-formação seja um processo de produção de conhecimentos sobre os problemas vividos pelo sujeito em sua ação docente, de acordo com Santos (2005) 
A pesquisa-formação faz com que o objeto de pesquisa e os sujeitos da pesquisa sejam parte da formação, e isso promove as mudanças das práticas assim como dos sujeitos em formação.

Toda ação deve emergir dos problemas, temas e necessidades de todos os sujeitos pesquisadores. O pesquisador é coletivo, não se limita a aplicar saberes existentes, as estratégias e os saberes emergem da troca e da partilhar de sentidos de todos os envolvidos, conforme Santos (2005, p. 163)

Já Giovanni [...] destaca a importância da parceria na pesquisa-formação e elenca algumas características que definem o paradigma da pesquisa colaborativa, que são: (1) a pesquisa focaliza tanto questões práticas reais da escola quanto questões teóricas, (2) há um processo de respeito e crescimento mútuo na escola, (3) a estrutura colaborativa une os professores, encoraja novas interações e gera possibilidades para os professores poderem assumir novos papéis e exibirem lideranças, (4) o processo de interação do grupo e o conteúdo apreendido estreitam a lacuna entre o "saber fazer" e "implementar achados da pesquisa", e (5) os professores se tornam mais atentos à necessidade de melhorias quando se viabiliza para eles e com eles a análise e observação de seu próprio perfil. (GIOVANNI apud ROSA, 2017, p. 96-97).

A pesquisa-formação foi baseada nas tertúlias pedagógicas, conforme Girotto e Mello (2012). As tertúlias pedagógicas são momentos de reflexão onde os participantes podem expor seus sentimentos, recordações e pensamentos, fazendo com que cada professor possa se expressar e os que não se sentirem preparados tenham a liberdade de não falar.

$\mathrm{Na}$ pesquisa-formação levada a efeito, houve a participação ativa da coordenadora pedagógica, mediando os questionamentos e explicando alguns trechos lidos pelos professores, já que por diversos momentos eles tiveram dificuldade de entender determinadas partes do texto apresentado. Tal interferência fere a pureza da metodologia da tertúlia, por esta razão afirma-se que se baseou, se inspirou, nas tertúlias. Mas o espaço para as exposições, para o diálogo, para as elaborações pessoais e do grupo foi mantido, o que é próprio da tertúlia.

Conforme Girotto e Mello (2012) a dinâmica da tertúlia inicia com o professor que deseja falar no encontro (aquele que selecionou um trecho, lembrou de algo ou faz algum questionamento). Durante os encontros, os professores fazem a leitura do texto e dialogam sobre o que entenderam, o motivo de terem escolhido determinado trecho, suas dúvidas e relações estabelecida com seu trabalho diário e com suas vidas. Os demais colegas questionam, concordam ou discordam do trecho apresentado e isso traz as diversas reflexões e à uma conclusão. É importante estabelecer a reflexão da teoria e da prática em todos os encontros.

Tal pesquisa-formação justifica-se considerando o contexto de ênfase na formação continuada dos professores como uma das formas de promover melhorias no aprendizado e as 
próprias necessidades formativas e expectativas dos docentes participantes desta pesquisaformação.

\section{Universo, sujeitos, desenvolvimento}

O CEI em que foi feita a pesquisa-formação possui duzentas e cinquenta e seis (256) crianças de zero a três anos e onze meses de idade matriculadas. A escola possui em seu quadro docente quarenta e oito (48) professores de Educação Infantil, que tomaram posse do cargo através de concurso público.

Todos os professores da unidade escolar possuem graduação em Pedagogia e a grande maioria possui pós-graduação lato sensu em cursos diversos. Destes, vinte e dois trabalham no período das $7 \mathrm{~h}$ às $13 \mathrm{~h}$ e os outros vinte e dois no período das $13 \mathrm{~h}$ às $19 \mathrm{~h}$. Os momentos de formação são preparados para todos os professores, durante três dias da semana. O período da manhã e da tarde se encontram às terças, quartas e quintas das $7 \mathrm{~h}$ às $8 \mathrm{~h}$ e das $18 \mathrm{~h}$ às $19 \mathrm{~h}$, respectivamente. Ambos os grupos possuem um total de 108 horas de formação anual.

Este momento de formação está presente na Portaria 901 da Prefeitura do Município de São Paulo, publicada em 24 de janeiro de 2014, que dá orientações para a organização e formação continuada.

Durante muito tempo a formação oferecida na escola não abrangia a real necessidade dos professores. Com o constante atendimento ao quadro docente e às famílias do entorno escolar, a formação continuada precisava mudar, de forma que os professores pudessem mudar suas posturas e as famílias compreendessem a importância da educação infantil na vida das crianças.

Anualmente, no final de todo ano letivo, o grupo de professores escolhe um tema para ser trabalhado no decorrer do próximo ano, durante esses momentos de formação. Dentre os temas já escolhidos estão a Psicomotricidade, a Leitura e os Indicadores de Qualidade da Educação Infantil. No ano da pesquisa, o tema escolhido foi Tempos e Espaços na Educação Infantil.

A cada ano o coordenador busca trazer a importância de se trabalhar os diversos temas para que todas as dúvidas e dificuldades dos professores sejam sanadas. O tema escolhido no ano de pesquisa foi devido à escola estar localizada dentro de uma área verde onde os professores sentiam necessidade de pensar como utilizar de forma pedagógica os espaços, assim como implantar a rotina no trabalho com as crianças.

Com a formação anual montada, definiu-se que a pesquisa iniciaria no segundo semestre, e poderíamos trazer Maria Montessori que tem um olhar voltado para educação infantil. A 
escolha de uma obra escrita por Maria Montessori ocorreu após a percepção de que a educadora tratava especificamente da criança de zero a seis anos, por sua primeira formação ser medicina e ter trabalhado dentro de sua faculdade com crianças que possuíam necessidades especiais.

Após a escolha do livro, intitulado "A criança” (1936), iniciou-se a leitura para definição de quais capítulos seriam utilizados no decorrer da pesquisa. Buscavam-se textos que se aproximassem da realidade encontrada no CEI. Foram então selecionados pela coordenadora seis textos para leitura e reflexão, nos moldes das tertúlias pedagógicas, junto aos professores da unidade.

No primeiro dia de formação do segundo semestre os professores se reuniram e foi apresentado o projeto para os próximos meses, mostrando a importância da pesquisa e da participação de cada um no decorrer do semestre. Esta pesquisa seria fundamental para verificar as reais necessidades deles, assim como os ajudaria no trabalho diário. Neste momento foram apresentados os caminhos que a pesquisa teria: reuniões com leitura dos textos separados para cada professor, reflexão com o grupo e gravação das falas para transcrição, relato escrito da experiência com o clássico da educação e eleição das categorias de análise da pesquisa. Todo este material seria utilizado na pesquisa via transcrição escrita das falas dos professores e registro escrito por eles.

Primeiramente, seriam programados alguns momentos para leitura de textos de Maria Montessori, definidos anteriormente, e alguns professores questionaram a escolha da autora. Neste momento houve uma breve apresentação da obra que seria utilizada e percebeu-se que a mesma trabalhou muito com crianças pequenas e seu olhar para elas era diferenciado. A autora escolhida traria contribuições importantes para os professores e suas práticas.

Após a leitura, num segundo momento, seriam feitas discussões com os grupos, tendo em vista a utilização das tertúlias pedagógicas para orientar estes momentos. Tudo seria registrado com a transcrição de todas as falas dos participantes da pesquisa. Novamente houve o questionamento sobre o que seriam as tertúlias pedagógicas e como os professores seriam auxiliados neste processo.

Explicou-se que seriam momentos de conversa, práticas que já haviam acontecido o decorrer do primeiro semestre, para que os professores pudessem expressar seus sentimentos e pensamentos e relacioná-los aos textos lidos. Estes momentos seriam gravados para futura pesquisa, tendo em vista a contribuição que cada professor faria. Dentre os quarenta e oito professores da unidade escolar, participaram quarenta e cinco professores da pesquisa. Um dos professores que se recusou a participar alegou ter problemas pessoais junto à coordenação 
pedagógica, o outro não quis expor suas opiniões e o terceiro foi designado para o cargo de Assistente de Direção. Foi acordado inclusive a utilização dos nomes reais dos professores na pesquisa, com a assinatura do Termo de Consentimento preparado. Os professores então participariam de um terceiro momento da pesquisa, o relato escrito sobre a experiência de leitura e diálogo.

Dar aos professores a oportunidade de ler textos escritos por Maria Montessori, e não textos escritos sobre a autora, fez com que os professores tivessem maior participação e envolvimento junto à pesquisa, oportunizando momentos de ampliação de vocabulário e saberes necessários às suas práticas.

Após a apresentação deste projeto de trabalho, foram acordados os textos a serem lidos e discutidos, a saber: As delicadas estruturas psíquicas (MONTESSORI, 1936, p. 50-62); A inteligência (idem, p.74-83); A mão (Id. Ibid. p. 93-99); A atividade motora (id. Ib. , p 108-111); O ambiente (1965, p. 42-58); A educação da criança (p. 125-137) e, A preparação espiritual do professor (p. 165-169).

\section{As categorias de análise da pesquisa}

Visando a melhor organização para a análise dos dados coletados, a partir da pesquisa realizada foram pensadas três categorias que nos auxiliam na melhor compreensão e trazem fundamentos elencados nos conceitos que os professores descreveram: (1) a função do professor; (2) a criança/aluno; e (3) a experiência formativa. A argumentação desenvolvida se deu em torno das categorias de análise oriundas do cruzamento dos dados coletados nos momentos de pesquisa-formação com as referências teóricas e os documentos da pesquisa, de modo a analisar o material produzido nos encontros formativos junto aos professores. Neste texto serão expostas as considerações pertinentes a primeira categoria de análise.

A primeira categoria de análise pensada foi a função do professor, que buscou trazer o papel do professor e suas práticas junto às crianças. Diante dos textos lidos e refletidos, os professores trouxeram considerações sobre suas práticas pedagógicas e também se reavaliaram, pois relataram práticas que tinham e atualmente não possuem mais, por toda formação continuada que é feita na escola.

\section{Categoria de análise: A função do professor}

Nóvoa (2009) acredita que o professor precisa desenvolver duas competências para sua prática. A primeira delas é a organização, pois o professor deve ser um organizador de 
aprendizagens e do seu trabalho escolar e a segunda é a compreensão do conhecimento, pois antes de transmitir o conhecimento é preciso entender e ser capaz de reelaborar e reorganizar as etapas para garantir o êxito da aprendizagem.

Já Tardif (2014) descreve que muitas vezes as pessoas se preocupam com o que os professores devem ou não fazer em sala de aula, mas nunca se preocupam em saber o que efetivamente eles fazem.

O professor deve se preparar interiormente e conhecer a si mesmo e se auto avaliar, e essa avaliação de si próprio deve ser constante, a fim de que o professor possa fazer o seu melhor com as crianças deixando de lado o seu "eu", o seu "querer", levando em consideração os "quereres" das crianças, renunciando seu "ego", aberto para aprender e aprender com as crianças, mas para isso requer humildade, entendendo que a missão do professor é educar. (Prof ${ }^{a}$. Priscila)

Saviani (2007) relata que o trabalho docente é o "ato de produzir, direta e intencionalmente, em cada indivíduo singular, a humanidade que é produzida histórica e coletivamente pelo conjunto de homens" (p. 10).

Atualmente, os cursos de graduação em Pedagogia possuem em sua grade de aulas a especificação em Educação Infantil, o que facilita o trabalho do professor iniciante, porém somente esta formação não é suficiente, pois as funções do professor estão em constantes mudanças, e isso faz com que seja importante o professor se manter atualizado.

O trecho que eu li e que foi muito marcante para mim, foi onde ela diz que não basta para o professor ter somente formação acadêmica, mas que esse professor deve ter um conhecimento do seu "eu". Reconhecer seus defeitos, mas para que isso aconteça é preciso vencer o orgulho que é precedido pela ira. (Prof. Ana Rosa).

A ira é um dos pecados que domina e impede o professor de perceber seus defeitos, aliado ao orgulho, pois o professor muitas vezes não aceita interagir com outros professores e nem a opinião alheia. As relações sociais são necessárias na carreira docente. Normalmente os professores que se deixam dominar pela ira e orgulho juntam-se como forma de apoio uns aos outros. (Maria Montessori, A preparação espiritual do professor).

Analisar a função do professor de educação infantil é importante durante todo o processo de formação continuada dentro da escola, pois muitas vezes as funções do professor ainda são esquecidas e eles procuram trazer práticas caseiras para dentro da escola.

O documento Avaliação na Educação Infantil: aprimorando os olhares, da Secretaria Municipal de Educação de São Paulo conceitua o perfil do professor da educação infantil. Redigido em 2014, traz que o 
$\mathrm{O}$ (a) educador(a) da Infância deve ter um papel fundamental como "observador participativo", que intervém para oferecer, em cada circunstância, os recursos necessários à atividade infantil, de forma a desafiar, promover interações, despertar a curiosidade, mediar conflitos, garantir realizações, experimentos, tentativas, promover acesso à cultura, possibilitando que as crianças construam culturas infantis. (SÃO PAULO, 2014, p. 15).

Já Maria Montessori conceitua o preparo do professor de educação infantil, ao “insistirmos em afirmar que o professor deve preparar-se interiormente; estudando-se a si mesmo, [...], a fim de conseguir suprimir os próprios defeitos ocultos na consciência necessitamos de ajuda externa, de uma certa instrução; é indispensável que alguém nos indique o que devemos ver em nós mesmos” (MONTESSORI, 1936, p. 165)

Venho aprendendo com o tempo a respeitar e ver com outros olhos a curiosidade, o interesse da criança por aquilo que a cerca. Compreendendo e aceitando essa necessidade do toque e pegar para ver. (Prof ${ }^{\text {. Graciane). }}$

Trazendo um pouco para a vida pessoal, lembro que nunca escondi ou tirei do alcance dos meus filhos produtos ou objetos que, vamos dizer assim, não deveriam lhes interessar. Ao contrário, ficava cada coisa em seu lugar e havia muito diálogo. Procuro agir assim em sala de aula porém assumo que foi (e está sendo) um longo processo. Estou aprendendo a confiar nos meus alunos e conseguindo observá-los, orientá-los e mostrar-lhes confiança em seus momentos de curiosidade. Hoje vejo tudo com mais calma e fico sempre por perto para dar apoio e ajudar no que precisarem, vibro com toda ousadia que apresentam. (Prof ${ }^{a}$. Graciane).

Tanto professores quanto crianças possuem uma relação dialética, de troca constante de informações, onde um se desenvolve na interação com o outro. (BRASIL, 2014). Na prática pedagógica é dever do professor observar algumas atitudes e práticas dos alunos, como muitos pontuam a seguir no decorrer da pesquisa.

Observamos e trabalhamos com o desenvolvimento da fala e do deslocamento no CEI. Quando em nossas rodas de história e conversas fazemos as crianças serem ouvidas e consideradas, estamos priorizando esse desenvolvimento e auxiliando na ampliação do repertório infantil com palavras e canções. (Prof ${ }^{a}$. Sara).

Infelizmente muitos adultos, sem se dar conta, reprimem o crescimento das crianças, negando à criança, sua oportunidade de exploração, curiosidade, seu crescimento, muitas vezes por cuidado excessivo, por achar que a criança não é capaz, não irá conseguir, quando digo adultos me refiro a professores, responsáveis e pais. (Prof ${ }^{a}$. Josilene).

O professor também precisa colocar-se no papel de aprendente. Um professor aprendente é aquele que se permite aprender na relação com seus alunos, que mesmo muito pequenos tem a ensinar sobre quem são, o que sabem, o que gostam, bem como aprender com seus pares. A questão que ainda se faz 
presente no educador é buscar argumento para justificar seus atos, mesmo que isso coloque a criança nesse governo primitivo, já que ele é que ensina e para o outro só resta a tarefa de aprender. Neste aprender muitas vezes não há aprendizagem alguma. (Prof ${ }^{\mathrm{a}}$. Telma).

A importância do ambiente, ter um olhar cuidadoso, deixar esse ambiente seguro, acolhedor para que as crianças possam exercer e praticar suas descobertas e curiosidades, experimentar coisas novas. Em sala de aula, cada vez precisamos ser mais flexível, ter um olhar atento com nossas crianças, criar possibilidades para atender esse desejo, essa curiosidade de nossas crianças. (Prof ${ }^{a}$. Josilene).

O adulto, principalmente aquele que está inserido na educação deve estar muito atento às necessidades, curiosidades das crianças, correspondendo suas expectativas de conquistas, descobertas e desafios. Esse olhar deve estar inteiramente voltado para a criança que não seja podada e reprimida em suas ações. (Prof ${ }^{a}$. Viviane).

Devemos como educadores, ter ou desenvolver um olhar sensível, para observar a individualidade de cada criança. Uns tem predisposição para diferentes áreas do conhecimento. Deve-se respeitar isso. As aptidões de cada criança, de modo a não limitá-la em suas capacidades, nem moldá-la ao nosso prazer, para atender aos gritos sociais. (Prof $f^{a}$. Ana Rosa).

Devemos estar atentos às manifestações dessas crianças, pois o que foge ao 'natural' pode ser um pedido de socorro. O olhar sensível do professor faz a diferença porque ao observar atitudes diferentes, perturbadoras em nossos alunos podemos procurar ajuda-los através de diálogo com as famílias, para assim conhecer melhor, pesquisar e buscar juntos trabalhar da melhor maneira para que essa criança se desenvolva e consiga avançar cada vez mais. O olhar sensível, atento e vivo, deve permanecer no professor. (Prof ${ }^{a}$. Sara).

As manifestações das crianças somente são reconhecidas quando o professor tem a possibilidade e se abre a observar com atenção e mudar sua postura diante das diversas formas de manifestação infantil. Cada criança tem sua especificidade, assim como cada professor, e é preciso sensibilizar o olhar para que se possa intervir e auxiliar no desenvolvimento das crianças.

Muitas vezes as crianças calmas nos passam despercebidas, são as agitadas que sempre estamos mediando, com esse texto me veio a reflexão de um olhar mais atento com aquelas crianças tachadas de calmas também. Todos merecem ter nosso olhar sensível. (Prof $f^{a}$. Josilene).

É importante que o adulto tenha a consciência, o discernimento e o respeito de promover momentos de reflexão para que cada criança, nas suas individualidades, se desenvolvam psiquicamente, emocionalmente, fisicamente e cognitivamente. (Prof ${ }^{a}$. Viviane).

Nós adultos temos um papel importante de como intervir e classificar estes períodos que podem ser conflitos interiores e que muitas vezes, acredito na maioria, classificamos como birra, falta de limites e que podem ser conflitos interiores e que se agravam precisamente com um tratamento errado. Confesso que em vários momentos me deparei imaginando (durante a leitura) se não errei 
com algumas crianças se não queriam me dizer algo quando apresentaram esses períodos sensíveis. (Prof ${ }^{a}$. Maria Angela).

Ao realizarmos o estudo do capítulo 7 da obra, "As delicadas estruturas psíquicas", confesso que saí mexida e reflexiva no meu papel de educadora, principalmente em uma faixa etária onde as crianças são tão pequenas e aparentemente não se expressam como crianças mais velhas que já falam/verbalizam seus anseios, desejos e necessidades. (Prof ${ }^{a}$. Daniela Langone).

Nem sempre aquele comportamento que encaramos como birra, malcriação o é de fato. Muitas vezes, ou na maioria das vezes, lidamos com isso de forma negativa por não estarmos bem informados sobre o assunto. (Prof ${ }^{a}$. Graciane).

Tardif (2014) conceitua a importância do trabalho do professor quando diz que seus saberes parecem estar somente nas constantes transações entre o que são e o que fazem, pois o ser envolve as emoções, cognição e expectativas, além da história de vida pessoal deles, e o fazer diz respeito ao ensinar. Estes dois conceitos estão interligados.

Os saberes de um professor são uma realidade social materializada através de uma formação, de programas, de práticas coletivas, de disciplinas escolares, de uma pedagogia institucionalizada e, ao mesmo tempo, dos saberes dele. (TARDIF, 2014, p. 16).

A importância de sermos mediadores e prepararmos ambientes favorecedores, onde a criança encontre possibilidades de desenvolver-se, aprender, crescer, pois o ambiente influencia de forma positiva ou negativa em tudo o que o ser humano aprende. (Prof ${ }^{a}$. Graciane).

Podemos refletir sobre nossa prática e de quanto nós adultos e educadores subestimamos e até sufocamos nossas crianças com saberes que julgamos importantes, mas que para elas talvez não sejam. Não damos importância aos mínimos detalhes. (Prof ${ }^{a}$. Andrea).

Montessori diz que o professor tem a sua frente crianças, seres indefesos que aceitam tudo que lhes é proposto e por este motivo o professor precisa refletir profundamente sobre suas atitudes junto a este grupo, para que as crianças não passem por traumas. O adulto domina a criança simplesmente por ser adulto, por isso deve se auto avaliar sempre, expelindo de seu coração a ira e o orgulho, se tornando humilde para reconhecer seus erros.

O adulto tem dificuldade de deixar a criança tocar nos objetos, tirar do lugar e de ter que se conter a não interferir, sem por limites, deixar a criança explorar com as mãos. Muitas vezes, nós adultos, nos pegamos intervindo nas descobertas das crianças. Por cuidado', esquecemos que a criança e seu conhecimento se dá sobre a exploração com as mãos. A criança precisa tocar nos objetos e precisamos estar atento paras não reprimir seu crescimento. (Prof ${ }^{a}$. Marilu).

É preciso ser humilde e mudar nossas atitudes perante a criança, não agindo como detentor do saber, mas dando vozes as nossas crianças, dando ouvidos às 
necessidades dos nossos pequenos, valorizar as múltiplas linguagens das crianças, não deixando que se percam. (Prof ${ }^{a}$. Priscila).

Por mais doloroso que seja assumir, já fui uma professora assim, que se achava dona do saber, superior aos alunos e que eles nada tinham a oferecer. Hoje em dia minha visão é outra...Consigo me surpreender, perceber e aprender com tudo o que meu aluno oferece. Consigo olhá-lo com outros olhos e buscar algo pra acrescentar em sua bagagem. (Prof a Graciane).

O professor deve preparar-se interiormente estudando a si mesmo com metódica constância a fim de conseguir suprir os próprios defeitos mais enraizados, que constituem um obstáculo às suas realizações com as crianças. Muitas vezes na ânsia de cumprir nossa rotina não enxergamos as reais necessidades das crianças. (Prof ${ }^{a}$. Maria Angela).

Nem todo processo de formação de um professor baseia-se em técnicas e teorias de vários autores: não basta. O professor deve ter sabedoria e humildade para reconhecer seus próprios defeitos. (Prof ${ }^{\text {. Ana Rosa). }}$

O professor não é o soberano, detentor do saber, aquele que não tem defeito, acima de tudo ele é um ser humano que erra, que está em constante aprendizado, e muitas vezes não se dá conta de seus defeitos dificultando a compreensão das crianças. (Prof ${ }^{a}$. Maria Valmira).

O professor deve refletir a práxis docente e esse seria o ponto crucial do que será levado nas práticas pedagógicas, sempre deverá ser levado em consideração os efeitos da ação-reflexão-ação, para sempre melhorar e evoluir enquanto profissional para garantir o êxito do educando. (Prof ${ }^{a}$. Thiely).

\section{Considerações finais}

É ininterrupta a reflexão sobre formação continuada de professores e o potencial da ação formativa do coordenador pedagógico. Partindo de toda pesquisa realizada no CEI, durante a proposta de formação com foco nos textos escritos por Maria Montessori em 1936, conseguiu-se evidenciar a necessidade de conhecer as crianças em suas especificidades e também dinamizar o desenvolvimento profissional de cada participante através de uma ação formadora do coordenador, permeando toda a prática pedagógica.

O crescimento pessoal e profissional de todos os envolvidos ficou claramente evidenciado durante a formação, e todos avançaram nas trocas de experiências, leituras e entendimento dos textos propostos e dos textos lidos.

Todo processo de organização da pesquisa, escolha de material e conteúdos a serem trabalhados ocorreram a partir das experiências do grupo e também da coordenadora pedagógica, que detectou caminhos para que a formação fosse produtiva e objetivasse o conhecimento e trocas de experiências. 
Com as teorias sendo trabalhadas no decorrer da formação, foi possível (re) construir, (re) significar e (re) avaliar o trabalho pedagógico, partido da ação-reflexão-ação que Donald Schön trabalha em um de seus livros, pois acredita que o aprendizado só acontece a partir do fazer.

O processo de formação continuada deve dialogar com os saberes trazidos pelos professores, sejam da formação profissional (pedagógicos), disciplinares (campos do conhecimento: linguagem, ciências exatas, ciências biológicas, entre outros), curriculares (o que deve ser transmitido aos alunos) e experienciais (vivências dos docentes em sala de aula). É importante compreender o professor como um dos sujeitos do processo de aprendizagem, dividindo suas dúvidas e avanços.

É importante o relato de uma das professoras participantes da pesquisa que em sua graduação conheceu alguns textos de Maria Montessori, porém somente nesta pesquisa teve maior entendimento sobre a autora, pois acredita que teve oportunidade de compartilhar experiências e atualmente conhece o espaço escolar por trabalhar a muitos anos na Prefeitura de São Paulo.

O trabalho inspirado nas tertúlias pedagógicas ofereceu aos professores a oportunidade de trocarem informações sobre seus anseios, medos e angústias, mas também oportunizaram reconhecimento de momentos de alegria e satisfação ao longo de toda a pesquisa.

Com o desenvolver da pesquisa-formação, os professores passaram a se auto avaliar e reconhecer o quanto precisavam avançar nas suas próprias concepções, seja sobre as crianças ou sobre suas práticas diárias. Perceberam a necessidade de envolver as crianças no que propunham e também a importância de escutar uns aos outros, nas relações sociais que se estabeleceram e se fortaleceram no grupo de formação.

Elementos de uma proposta colaborativa e investigativa estiveram presentes quando da parceria durante a explicação dos textos apresentados, no respeito que se iniciou no grupo partindo do texto que evidenciou o trabalho do professor e a perceptível consistência no grupo quanto às suas decisões e relações.

O trabalho colaborativo e participativo também se apresentou no grupo, pois ao terem dificuldades na leitura de algum texto apresentado, os participantes conversavam entre si e buscavam informações antes do grupo apresentar suas opiniões, o que foi avaliado por todos como muito positivo.

A pesquisa evidenciou que alguns professores não aceitam as orientações propostas no contexto escolar, partindo de sua recusa por motivos diversos, inclusive por ainda pensarem que 
já recebem seu salário e por serem servidores públicos não precisam aprimorar seus conhecimentos, bastando somente o que já possuem de experiência em sala de aula.

Acredita-se que o processo de formação continuada em serviço, dentro da escola, tenha surtido efeito positivo em quase todos os envolvidos, pois as relações se fortificaram, promovendo interação e maior participação nos temas relacionados à prática pedagógica, além da mudança significativa no olhar dos professores. Ao trocarem experiências oportunizaram maior envolvimento nas atividades e propostas apresentadas, o que corroborou a importância de uma prática efetiva de formação desencadeada pelo coordenador pedagógico no exercício de suas funções.

\section{Referências}

ARCE. A.; DANDOLINI, M. R. A formação de professores de Educação Infantil. Algumas questões para se pensar a profissional que atuará com crianças de 0 a 3 anos. In. ARCE, A.: MARTINS L. M. Ensinando aos pequenos de zero a três anos. Campinas: Alínea, 2009 BISSACO

BRASIL. Lei n. 9.394, de 26 de dežembro de 1996. Lei de Diretrizes e Bases da Educação Nacional (LDB). Brasília, 1996.

BRASIL. Lei n. ${ }^{0} 13.005$, de 25 de junho de 2014. Aprova o Plano Nacional de Educação - PNE e dá outras providências. Diário Oficial da União de 26/6/2014, Seção 1, p. 1, Edição Extra.

CAMPOS, M.M. Questões sobre a formação de professores de educação infantil. Laplage em Revista, v.4, n. especial, p. 9-22, set./dez. 2018.

DAVIS, C.L.F.; NUNES, M.M.R. (orgs.). Formação continuada de professores: uma análise das modalidades e das práticas em estados e municípios brasileiros. São Paulo: FCC/DPE, 2012.

GIROTTO, V.C.; MELLO, R. O ensino da leitura em sala de aula com crianças: a tertúlia literária dialógica. Revista InterAção,v.37, 67-84. Disponível em: https://doi.org/10.5216/ia.v37i1.18869. Visualizado em: 20 fev 20.

LIBÂNEO, J.C. A identidade profissional dos professores e o desenvolvimento. In: Organização e gestão da escola: teoria e prática. 6 ed. São Paulo: Heccus Editora, 2015.

MONTESSORI, M. A criança. São Paulo: Círculo do Livro, 1936.

MONTESSORI, M. O ambiente. In MONTESSORI, M. Pedagogia Científica: a descoberta da criança. São Paulo: Flamboyant, 1965, p. 42-58.

NOVOA, A. Professores: imagens do futuro presente. Portugal: Educa, 2009. 
ROSA, E. C. C. Projetos escolares como espaço de formação colaborativa: experiência de uma escola pública da Zona Leste de São Paulo. Dissertação de mestrado, 2017, Universidade Nove de Julho, São Paulo, 2017.

SANTOS, E.O.Educação online:cibercultura e pesquisa-formação na prática docente. Tese (doutorado) -Universidade Federal da Bahia, 351 f. Bahia, 2005.

SAVIANI, Demerval. Pedagogia: o espaço da educação na universidade. Cadernos de Pesquisa, v. 37, n. 130, p. 99-134, jan-abr 2007.

SÃO PAULO. Secretaria Municipal de Educação. Diretoria de Orientação Técnica. Orientação normativa $n^{\circ}$ 01: avaliação na educação infantil, aprimorando os olhares. São Paulo: SME/DOT, 2014.

SÃO PAULO. Portaria 901, de 24 de jan de 2014. Dispõe sobre Projetos Especiais de Ação (PEAs). São Paulo, jan 2014.

SÃO PAULO. Decreto Municipal no 54.453, de 10 de outubro de 2013. Fixa as atribuições dos profissionais de educação que integram as equipes escolares das unidades educacionais da rede municipal de ensino. São Paulo: Diário Oficial da Cidade de 11/10/2014, p. 1-3.

SCHÖN, D. Educando o profissional reflexivo: um novo design para o ensino e a aprendizagem. Porto Alegre: Artes Médicas Sul, 2000.

TARDIF, M. Saberes docentes e formação profissional. 14. ed. Petrópolis: Vozes, 2014.

Recebido em: 24 maio 2019 / Aprovado em: 27 set. 2019

\section{Cite como (ABNT NBR 6023:2018)}

BIOTO-CAVALCANTI, Patricia Aparecida; OLIM, Michele Pimentel. O papel do coordenador pedagógico numa experiência de formação colaborativa de professores. Dialogia, São Paulo, n. 34, p. 260-276, jan./abr. 2020. Disponível em: https://doi.org/10.5585/Dialogia.N34.13973. 